\title{
BMJ Open Translation and validation of the Chinese version of medical maximizer- minimizer scale: a cross-sectional study
}

\author{
Fenghua Lai (D) , ${ }^{1}$ Ling Pei, ${ }^{1}$ Shufan Yue, ${ }^{1}$ Xiaopei Cao, ${ }^{1}$ Haipeng Xiao, ${ }^{1}$ Yanbing Li, ${ }^{1}$ \\ Jin $\mathrm{Li}^{2}$
}

To cite: Lai F, Pei L, Yue S, et al. Translation and validation of the Chinese version of medical maximizer-minimizer scale: a cross-sectional study. BMJ Open 2021;11:e042432. doi:10.1136/ bmjopen-2020-042432

- Prepublication history and additional materials for this paper is available online. To view these files, please visit the journal online (http://dx.doi org/10.1136/bmjopen-2020042432).

Received 07 July 2020 Revised 13 December 2020 Accepted 18 December 2020

A) Check for updates

(C) Author(s) (or their employer(s)) 2021. Re-use permitted under CC BY-NC. No commercial re-use. See rights and permissions. Published by BMJ.

${ }^{1}$ Department of Endocrinology, The First Affiliated Hospital, Sun Yat-sen University, Guangzhou, China

${ }^{2}$ Department of Geriatrics, The First Affiliated Hospital, Sun Yat-sen University, Guangzhou, China

Correspondence to

Professor Jin Li;

lijin8@mail.sysu.edu.cn

\section{ABSTRACT}

Objective Medical overutilisation and underutilisation affect optimal healthcare. The Medical MaximizerMinimizer Scale (MMS) was developed to assess individual medical maximising and minimising tendencies. Despite significant improvement in the healthcare system over the past four decades, no psychometric scales to examine treatment maximising and minimising preferences are available in China. This study aimed to translate the MMS into Chinese and examine its reliability and validity in a Chinese population.

Design This cross-sectional study was conducted in December 2019 through an online survey panel. Methods The MMS was translated into a Chinese version (CN-MMS) using a forward-backward translation procedure. Next, a random online survey of the general population in China was conducted. Exploratory factor analysis (EFA) and confirmatory factor analysis were performed to examine the underlying factor structure of the CN-MMS. The internal consistency reliability of the scale was determined using Cronbach's $\alpha$ coefficient and corrected item-total correlation. A multivariate linear regression analysis was used to examine associations between medical maximising and minimising preferences and demographic variables in the Chinese population. Results This study included 984 participants aged 18-80 years. The CN-MMS retained 10 items, and the EFA supported a two-factor structure. The model fit for this two-factor structure of the CN-MMS was acceptable with $\chi^{2} / \mathrm{df}=3.7$, comparative fit inde $x=0.958$, goodness-of-fit index $=0.951$, Tucker-Lewis Index $=0.944$ and root mean square error of approximation $=0.074$. The scale had a Cronbach's $\alpha$ coefficient of 0.864 , corrected item-total correlation of $0.451-0.667$, and test-retest reliability of 0.815. Significant predictors of CN-MMS total score were nationality and household monthly income.

Conclusions The CN-MMS showed satisfactory psychometric properties. Therefore, it can be used to investigate the individual medical maximising and minimising tendencies among the general Chinese population.

\section{INTRODUCTION}

Over the past four decades, China has achieved significant improvement in providing efficient and affordable healthcare services to a large portion of its population.

\section{Strengths and limitations of this study}

The Medical Maximizer-Minimizer Scale was translated into Chinese using the standard forwardbackward translation procedure.

- This study included a large sample that was diverse in terms of participant age, gender and education.

- The participants were recruited using an online survey, so individuals without computer literacy or a smartphone might be excluded.

- Bias was inevitable, because this investigation relied on participants' self-report.

- The lack of existing research on the topic of medical maximising and minimising preferences in China made it difficult to properly compare our results with those of previous studies.

Notably, the government implemented more than five large-scale waves of healthcare reform since the 1950 s to meet the rapid increase in demand for an efficient medical service system. From 2003 to 2011, social medical insurance coverage in China increased from $29.7 \%$ to $95.7 \%$. $^{1}$ Additionally, the life expectancy reached 74.8 years in 2010 compared with 67.9 years in $1981 .^{2}$ In many urban areas, people have access to lifesaving medicine to treat illnesses that previously would have killed or disabled affected individuals. ${ }^{3}$ However, previous studies have revealed that many widely used tests and treatments have limited value in terms of saving lives or improving quality of life. ${ }^{45}$ There was growing recognition that medical interventions are not always helpful. ${ }^{6}$ Hence, a critical question is how people decide to take action and do something when it comes to their health.

The concept that individuals vary in their approach to medical interventions has long been recognised by physicians, but was formalised in 2011 by Groopman and Hartzband in their book 'Your Medical Mind'. They postulated that certain individuals 
were 'medical maximizers' whereas others were 'medical minimizers,' with these two groups inherently differing in their preferences for more or less medical care, respectively. Subsequently, this concept was quantified into a validated 10-item Medical Maximizer-Minimizer Scale (MMS). ${ }^{8}$ This scale is used to measure individual medical maximising and minimising tendencies and has been shown to predict a number of self-reported medical utilisation outcomes, including medication use, vaccination, frequency of physician visits, blood draws and hospital visits. ${ }^{8}$ For instance, among patients with thyroid cancer who have been declared disease free, maximizers preferred to do more physician visits and imaging tests. ${ }^{9}$ The scale was distinct from hypochondriasis, distrust in medicine, healthcare access and health status, and also predicted a variety of hypothetical testing and treatment preferences. For example, relative to a person with minimising preferences, a person with maximising preferences was more likely to report wanting prostate-specific antigen screening for prostate cancer, ${ }^{10}$ MRI evaluation of migraine headache, surgery rather than physical therapy for back pain, continued chemotherapy rather than palliative care for terminal cancer, ${ }^{8}$ and surgical management of renal incidentalomas. ${ }^{11}$ This scale may provide researchers with insight into healthcare utilisation patterns for individuals across health contexts. Knowledge of such utilisation patterns could be useful in tailoring health information, explaining health-related behaviour, and enhancing patient-provider communication. When physicians and their patients share the same orientation, this might enhance communication quality and patient satisfaction. Furthermore, identifying these more general medical maximising and minimising preferences could be instrumental in achieving high-quality communication about complex issues like overdiagnosis and overtreatment. ${ }^{8}$ Therefore, identifying individuals with general maximising versus minimising tendencies could also be important.

However, few studies have evaluated residents' medical maximising and minimising preferences in China. The absence of locally validated instruments has prevented assessment of public maximising and minimising preferences for healthcare utilisation in China. Therefore, this study aimed to translate the MMS into Chinese and test the psychometric properties of the scale in a Chinese population.

\section{METHODS}

\section{Instrument}

The MMS is a self-reported instrument which consists 10 items and measures two factors: a single factor loaded by all 10 items, another factor cross-loaded by items 1-3. Reponses are on a 7-point Likert scale (strongly disagree, disagree, somewhat disagree, neither agree nor disagree, somewhat agree, agree and strongly agree). Except for one item (item 5), numerical scores from 1 to 7 are assigned to each response. Item 5 is reverse scored (from
7 to 1$)$. The scores for each item are added to create a total score ranging from 10 to 70 . The MMS has a natural midpoint of score 40 indicating no strong preference for maximising or minimising, with scores below 40 indicating medical minimising and scores above 40 indicating medical maximising.

\section{Translation}

After obtaining permission from the original authors, a Chinese version of the MMS (CN-MMS) was developed using a forward-backward translation procedure. ${ }^{12}$ First, the forward translation was performed independently by two bilingual translators whose mother tongue was Chinese. One translator, the author of this article (FL), was familiar with the concept of the scale. The other translator was a professional translator with no knowledge of research background. Second, a bilingual native Chinesespeaking health professional who was not involved in the forward translation resolved discrepancies and synthesised the most suitable forward translation version. Third, the reconciled forward translation version of scale was literally back translated into English independently by two bilingual native English speakers who were fluent in Chinese and blinded to the original English version. Finally, an expert committee consisting of one methodologist, all translators and researchers reviewed all previous steps of translation to select the most appropriate translation for each item.

The pretest was conducted among 20 adults aged 25-65 years from the physical examination centre at the First Affiliated Hospital, Sun Yat-sen University to investigate the acceptability of the final translated version of MMS. Each participant was asked to complete the scale within $10 \mathrm{~min}$. Face validity was confirmed. Wording and contents were checked. Each participant was asked whether the words and terms used in the Chinese version were clear, relevant, and comprehensible. All 20 participants agreed that each item of the final translated version of MMS was straightforward and easy to understand. This final translated version had the same number of items as the original version (online supplemental table S1).

\section{Participants and data collection}

A cross-sectional and descriptive design was used in this study. Participants were recruited from an online survey panel (SO JUMP) in December 2019. Almost 100 million regular members in the SOJUMP panel, which is currently the largest online survey platform in China. All members consented to being contacted via Tencent QQ or WeChat (the most commonly used social networking platform in China). On completing questionnaires, panel members receive points that they can exchange for cash, gift cards or electronics. A test-retest study was conducted among 50 panel members (27 males, 23 females, aged $18-70$ years). At time 1 survey, 50 participants completed the CN-MMS and provided their Tencent QQ or WeChat ID. The IDs were used to contact these participants 2 weeks later to take part in the time 2 survey. Next, 1000 members of 
SO JUMP panel were randomly invited to participate in a formal investigation to assess the validity and reliability of the CN-MMS. In this study, participation was completely voluntary and anonymous. Besides the information of the CN-MMS, demographic characteristics of the participants (age, gender, nationality, etc) were collected. Participants with incomplete data were excluded from the analyses.

\section{Statistical analysis}

The data were statistically analysed with SPSS V.25.0 and AMOS V.22.0 (IBM Corporation). Continuous data were presented as mean $\pm \mathrm{SD}$ and categorical data were expressed as percentages. Skewness and kurtosis were computed for each item and the data were considered normally distributed when the values ranged from -2 to $+2 .{ }^{13}$ Exploratory factor analysis (EFA) and confirmatory factor analysis (CFA) were performed to investigate the underlying factor structure of the CN-MMS. The participants were randomly divided into two groups, half for EFA and the other half for CFA. In the EFA, a principal component analysis (PCA) with varimax rotation was performed with the 10 scale items. The sampling adequacy for the factorability was assessed using the Kaiser-Meyer-Olkin measurement and Bartlett's test of sphericity. When Bartlett's test of sphericity was significant $(\mathrm{p}<0.05)$ and the $\mathrm{KMO}$ was $>0.60$, the dataset was considered appropriate for PCA.

AMOS software was used for the CFA. The primary measurement indicators were the $\chi^{2} / \mathrm{df}(\mathrm{CMIN} / \mathrm{DF})$, comparative fit index (CFI), goodness-of-fit index (GFI), non-norm-fitting index (Tucker-Lewis Index, TLI) and root mean square error of approximation (RMSEA). These indices were used to verify the goodness of fit and acceptability of the model. When using the maximumlikelihood method to test the model, the model was considered to have reasonable fit and acceptability when the CMIN/DF was $<5$, CFI was $>0.9$, GFI was $>0.9$, TLI was $>0.9$ and RMSEA was $<0.08$. A multivariate linear regression analysis was performed to explore the underlying associations between demographic variables (age, gender, ethnicity, education, occupation status, household monthly income, living region, type of medical insurance, and history of chronic disease) and the CN-MMS. The internal consistency reliability of the scale was examined using the Cronbach's $\alpha$ coefficient and corrected itemtotal correlation. The minimum acceptable Cronbach's $\alpha$ coefficient was 0.7 . The corrected item-total correlation, representing the correlation between each item and the sum of the other items in the scale, was performed using the standard of 0.3 for inclusion. Kappa statistics (for each item) and intraclass correlation coefficient (ICC) (for CN-MMS scores) were used to assess test-retest reliability. Kappa coefficient above 0.6 and ICC above 0.7 were considered to indicate substantial agreement.

\section{Patient and public involvement}

There was no patient or public involvement in the development of the research design or in conducting the study. The participants were not consulted to develop the relevant outcomes or interpret the results.

\section{RESULTS \\ Descriptive statistics}

In total, 984 individuals aged $18-80$ years completed the questionnaire via the SO JUMP panel. Table 1 showed the sociodemographic characteristics of the study population. More than half of the participants were female (54.38\%) and came from urban areas $(63.52 \%)$. Most participants were of Han nationality $(95.33 \%)$ and did not suffer from chronic or severe diseases $(76.42 \%)$.

The mean score and distribution of each CN-MMS item were shown in table 2. These data were approximately normally distributed according to the skewness and kurtosis figures.

\section{Construct validity analysis}

Before commencing EFA, the factorability of the matrix in a sample $(\mathrm{n}=492)$ was evaluated. The KMO was 0.876 and Bartlett's test of sphericity was significant $\left(\chi_{45}^{2}=2210.528\right.$; $\mathrm{p}<0.001)$. Therefore, the matrix was not an identity matrix and was considered appropriate for factor extraction. The first PCA was performed to determine the likely number of factors. As shown in table 3, two factors that explained $62.246 \%$ of the variance both had initial eigenvalues $>1$. CFA was performed using the other sample $(n=492)$. The model fit for a two-factor structure of the CN-MMS was acceptable (CMIN/DF $=3.7$, CFI $=0.958$, GFI $=0.951$, TLI $=0.944$ and RMSEA $=0.074$ ). The factor loading of the items ranged from 0.56 to 0.84 (figure 1 ).

The results of the multivariate linear regression analysis were shown in table 4 . The CN-MMMS total score was correlated with nationality and household monthly income $(p<0.05)$. However, no statistically significant associations were found with age, gender, education, occupation status, region, type of medical insurance, and whether the participants had chronic or severe diseases.

\section{Reliability analysis}

The results of the reliability analysis showed that the CN-MMS had ideal internal consistency, with an overall Cronbach's $\alpha$ coefficient of 0.864 . As shown in table 5, the deletion of each item exclusively resulted in a decrease in the Cronbach's $\alpha$ coefficient (ranging from 0.840 to 0.860 , all Cronbach's $\alpha$ coefficients $<0.864$ ). The corrected item-total correlations for the items ranged from 0.451 to 0.669 , all of which were greater than 0.3 . Therefore, all 10 items were deemed integral to the questionnaire. A test-retest study conducted among 50 individuals showed good internal consistency reliability at time 2 survey (Cronbach's $\alpha$ coefficient $=0.815$ ). The Kappa coefficient of 10 items ranged from 0.651 to 0.888 (online supplemental table S2), and the ICC for total scores was 0.94 (95\% CI 0.70 to 0.98 ), which indicated substantial-to-good test-retest reliability. 
Table 1 Sociodemographic characteristics of the participants $(n=984)$

\begin{tabular}{|c|c|}
\hline Characteristics & $\begin{array}{l}\text { Mean } \pm \text { SD or } \\
n(\%)\end{array}$ \\
\hline Age & $32.5 \pm 11.06$ \\
\hline \multicolumn{2}{|l|}{ Gender } \\
\hline Female & $534(54.38)$ \\
\hline Male & $450(45.82)$ \\
\hline \multicolumn{2}{|l|}{ Ethnicity } \\
\hline Han & $938(95.33)$ \\
\hline Other minorities & $46(4.67)$ \\
\hline \multicolumn{2}{|l|}{ Education } \\
\hline Junior high school or lower & $43(4.37)$ \\
\hline Senior high school or trade school & $73(7.42)$ \\
\hline Bachelor's or associate's degree & $778(79.07)$ \\
\hline Master's degree or more & $90(9.14)$ \\
\hline \multicolumn{2}{|l|}{ Occupation status } \\
\hline Full time & $623(63.32)$ \\
\hline Part time & $175(17.78)$ \\
\hline Student & $91(9.25)$ \\
\hline Retirement & $45(4.57)$ \\
\hline Unemployed & $50(5.08)$ \\
\hline \multicolumn{2}{|l|}{ Household monthly income (Yuan/person) } \\
\hline$\leq 3000$ & 99 (10.06) \\
\hline $3001-5000$ & $258(26.22)$ \\
\hline $5001-8000$ & $314(31.91)$ \\
\hline$>8000$ & $313(31.81)$ \\
\hline \multicolumn{2}{|l|}{ Region } \\
\hline Rural & $359(36.48)$ \\
\hline Urban & $625(63.52)$ \\
\hline \multicolumn{2}{|l|}{ Type of medical insurance } \\
\hline Medical insurance for urban residents & 708 (71.95) \\
\hline New rural cooperative medical care & $136(13.82)$ \\
\hline Commercial insurance & $82(8.33)$ \\
\hline None & $58(5.90)$ \\
\hline \multicolumn{2}{|l|}{${ }^{*}$ Chronic or severe diseases } \\
\hline Yes & $232(23.58)$ \\
\hline No & 752 (76.42) \\
\hline
\end{tabular}

${ }^{*}$ Chronic or severe diseases included diabetes, hypertension, cardiovascular/cerebrovascular diseases, autoimmune diseases, chronic liver/kidney diseases, cancers or carcinomas, and severe trauma or surgery.

\section{DISCUSSION}

To our knowledge, this was the first study to examine the psychometric properties of a version of the MMS adapted for use in China. Our findings supported a twofactor structure with 10 items. Construct validity, discriminant validity and reliability analyses confirmed that the CN-MMS was reliable and valid for assessing individual
Table 2 Skewness and kurtosis tests of the Chinese version of Medical Maximizer-Minimizer Scale $(n=984)$

\begin{tabular}{cclc}
\hline Item number & Mean \pm SD & Skewness & Kurtosis \\
\hline 1 & $5.19 \pm 1.36$ & -0.996 & 0.844 \\
2 & $5.45 \pm 1.40$ & -1.060 & 0.760 \\
3 & $5.03 \pm 1.52$ & -0.643 & -0.243 \\
4 & $5.41 \pm 1.37$ & -1.038 & 0.918 \\
5 & $5.20 \pm 1.20$ & -0.939 & 0.996 \\
6 & $5.20 \pm 1.34$ & -0.712 & 0.042 \\
7 & $5.34 \pm 1.31$ & -0.988 & 0.919 \\
8 & $5.19 \pm 1.44$ & -0.705 & -0.016 \\
9 & $5.54 \pm 1.28$ & -1.010 & 0.934 \\
10 & $4.60 \pm 1.61$ & -0.338 & -0.776 \\
\hline
\end{tabular}

medical maximising and minimising tendencies among the Chinese general population.

In this study, the EFA and CFA jointly supported an independent two-factor structure for the CN-MMS, which differed from the results of the original version of the scale. ${ }^{8}$ The original MMS showed a bifactor model in

Table 3 Factor loadings of the Chinese Version of Medical Maximizer-Minimizer Scale $(n=492)$

\begin{tabular}{lcc}
\hline Item content & Factor $\mathbf{1}$ & Factor 2 \\
\hline $\begin{array}{l}\text { 4. When it comes to healthcare, the } \\
\text { only responsible thing to do is to }\end{array}$ & 0.866 & 0.156 \\
actively seek medical care. & &
\end{tabular}

1. It is important to treat disease even $0.862 \quad 0.169$ when it does not make a difference in survival.

$\begin{array}{lll}\begin{array}{l}\text { 7. I often suggest that friends and } \\ \text { family see their doctor. }\end{array} & 0.812 & 0.217 \\ \begin{array}{l}\text { 2. It is important to treat a disease } \\ \text { even when it does not make a }\end{array} & 0.755 & 0.258 \\ \text { difference in quality of life. } & & \\ \begin{array}{l}\text { 5. If I have a health issue, my } \\ \text { preference is to wait and see if the } \\ \text { problem gets better on its own before }\end{array} & 0.641 & 0.190 \\ \text { going to the doctor. }\end{array}$
8. When it comes to healthcare,
$0.123 \quad 0.781$

watching and waiting is never an acceptable option.

\begin{tabular}{lll}
$\begin{array}{l}\text { 9. If I have a medical problem, my } \\
\text { preference is to go straight to a doctor } \\
\text { and ask his or her opinion. }\end{array}$ & 0.201 & 0.772 \\
$\begin{array}{l}\text { 6. If I feel unhealthy, the first thing that } \\
\text { I do is to go to the doctor and get a } \\
\text { prescription. }\end{array}$ & 0.233 & 0.759 \\
$\begin{array}{l}\text { 10. When it comes to medical } \\
\text { treatment, more is usually better. }\end{array}$ & 0.121 & 0.679 \\
$\begin{array}{l}\text { 3. Doing everything to fight illness is } \\
\text { always the right choice. }\end{array}$ & 0.270 & 0.646 \\
$\begin{array}{l}\text { Variance explained (\% ) } \\
\end{array}$ & 45.963 & 16.283 \\
\hline
\end{tabular}




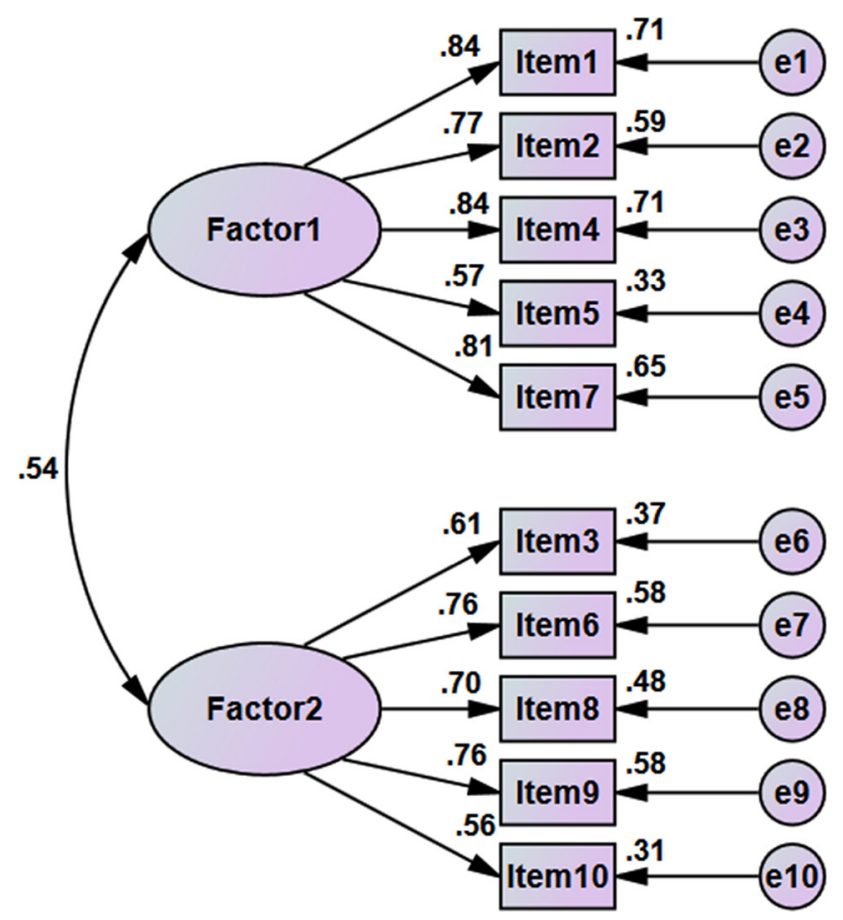

Figure 1 Standardised two-factor structural model of the Chinese version of the Medical Maximizer-Minimizer Scale.

which all 10 items loaded on a single factor, with items 1-3 also cross-loading onto another independent factor. Cultural differences were one possible reason for the different results. For example, Chinese people tend to be more conservative than Americans, ${ }^{14}$ and Chinese culture is rooted in traditional Confucianism and strong family cohesion. These conceptions affect people's way of life and attitudes towards medical decision-making. ${ }^{15}$ The CN-MMS showed an acceptable model fit for an independent two-factor structure $(\mathrm{CMIN} / \mathrm{DF}=3.7, \mathrm{CFI}=0.958$, GFI $=0.951$ and RMSEA $=0.074$ ), which was similar to the results obtained from the original MMS (CMIN/DF $=4.32$, $\mathrm{CFI}=0.956, \mathrm{GFI}=0.955$ and RMSEA $=0.075$ ). Further, the sample sizes of the present study and the original study
Table 5 Cronbach's $\alpha$ coefficient if the item was deleted and corrected item-total correlation $(n=984)$

\begin{tabular}{cll}
\hline $\begin{array}{l}\text { Item } \\
\text { number }\end{array}$ & $\begin{array}{l}\text { Cronbach's } \boldsymbol{\alpha} \text { if the } \\
\text { item was deleted }\end{array}$ & $\begin{array}{l}\text { Corrected item-total } \\
\text { correlation }\end{array}$ \\
\hline 1 & 0.840 & 0.657 \\
2 & 0.843 & 0.627 \\
3 & 0.855 & 0.495 \\
4 & 0.840 & 0.667 \\
5 & 0.853 & 0.499 \\
6 & 0.847 & 0.582 \\
7 & 0.840 & 0.669 \\
8 & 0.851 & 0.529 \\
9 & 0.848 & 0.568 \\
10 & 0.860 & 0.451 \\
\hline
\end{tabular}

were effectively equivalent. Therefore, the results of the validity analysis in both our study and the original study were reasonable and acceptable.

The reliability of the CN-MMS was assessed using Cronbach's $\alpha$ coefficient, item-total correlations and testretest. In this study, the high Cronbach's $\alpha$ coefficient indicated the CN-MMS was structurally consistent and balanced. ${ }^{16}$ The Cronbach's $\alpha$ values of the original scale ranged from 0.860 to 0.870 . Based on these results, the Cronbach's $\alpha$ coefficients were consistent between our study and the original study. ${ }^{8}$ The item-total score correlation coefficients were generally higher than 0.30 , which confirmed the CN-MMS had good internal consistency. In addition, the kappa coefficients for 10 items ranged from 0.651 to 0.888 , and the ICC for CN-MMS scores was 0.94 in the test-retest study. The results indicated that the CN-MMS had stable repeatability.

The CN-MMS total scores correlated with nationality and household monthly income, which confirmed the GN-MMS was valid. An interesting finding in this study was that

Table 4 A multivariate linear regression analysis on the impact of variables on total scores of the Chinese Version of Medical Maximizer-Minimizer Scale $(n=984)$

\begin{tabular}{lllllrrr}
\hline & Tolerance & VIF & B & SD & Beta & T test & P value \\
\hline Constant & $*_{-}$ & $*_{-}$ & 55.141 & 3.605 & ${ }^{*}-$ & 15.295 & $<0.001$ \\
Age & 0.771 & 1.296 & 0.009 & 0.030 & 0.011 & 0.038 & 0.758 \\
Gender & 0.973 & 1.028 & 0.486 & 0.597 & 0.026 & 0.815 & 0.415 \\
Ethnicity & 0.968 & 1.033 & 3.310 & 1.412 & 0.076 & 2.345 & 0.019 \\
Education & 0.796 & 1.256 & -0.295 & 0.567 & -0.019 & -0.521 & 0.603 \\
Occupation status & 0.860 & 1.163 & -0.285 & 0.280 & -0.035 & -1.019 & 0.308 \\
Household monthly income & 0.792 & 1.262 & 0.805 & 0.336 & 0.085 & 2.398 & 0.017 \\
Region & 0.466 & 2.144 & 0.396 & 0.892 & 0.021 & 0.445 & 0.657 \\
Type of medical insurance & 0.501 & 1.996 & -0.338 & 0.472 & -0.032 & -0.716 & 0.474 \\
Chronic or severe diseases & 0.882 & 1.134 & -0.890 & 0.735 & -0.041 & -1.210 & 0.227 \\
\hline
\end{tabular}

${ }^{*}$ Not available. 
nationality had a significant influence on people's medical maximising and minimising tendencies. Specifically, people from ethnic minority regions had lower total CN-MMS scores than those of Han nationality, which suggested that in general, ethnic minorities had minimising healthcareseeking tendencies. However, the historically marginalised racial minorities (especially Black Americans) consistently scored more maximising on average than White Americans in the original study. ${ }^{8}$ Hence, there did not appear to be a consistent direction of effect for minority vs majority group members across cultures. Previous studies reported that patients from ethnic minority groups in China may use less confrontation and more avoidance when coping with health issues. ${ }^{17-19}$ The factors underlying inequalities in healthcare utilisation between ethnic minority and non-ethnic minority populations are complex and varied. However, aspects related to income, employment, education, food security, healthcare policies and systems, social policies, social structures, health behaviours and cultural norms were all thought to play a role. ${ }^{20}{ }^{21}$ In this study, a significant association was found between high total CN-MMS scores and high household monthly income. Income was known to be an important determinant of healthcare. ${ }^{22}{ }^{23}$ People with higher incomes had been found to be exposed to increased intensity of health checks and had access to advanced medical treatment. ${ }^{24}$ Although a previous study found that large disparities still existed in health service utilisation between urban and rural regions in China, ${ }^{3}$ the multivariate linear regression analysis in our study showed no statistically significant association between treatment preferences and region. A reason for this may be policy support. Over the past two decades, the Chinese government introduced several strategies that aimed to reach remote and poor populations, including offering medical insurance to rural residents through the New Cooperative Medical Scheme and supplying free public health services via primary care facilities in rural regions. ${ }^{25}$

Several limitations should be considered when interpreting the findings of this study. First, the demographics of participants in this study were not exactly consistent with the latest population statistics of China. ${ }^{26}$ For example, the proportion of participants with junior high school or lower educational level was less than that in the Sixth National Population Census of China $(4.37 \%$ vs $38.79 \%)$. Participants in the present study were recruited using an online survey, which might have excluded individuals without computer literacy or a smartphone. Younger and highly educated members of the online survey panel might have been more likely to complete the survey, which could have artificially limited the representativeness of our study. However, previous studies failed to find differences in response patterns to online surveys on the basis of age, income or education. ${ }^{27} 28$ Therefore, an online survey is considered an alternative method for a questionnaire-based study. Second, bias was inevitable because this investigation relied on participants' selfreport. Third, the lack of existing research on the topic of medical maximising and minimising preferences in
China made it difficult to properly compare our results with those of previous studies. However, this has also highlighted the novelty of this study.

\section{CONCLUSIONS}

This study showed that the CN-MMS had satisfactory psychometric properties. The EFA and CFA supported a two-factor structure for the CN-MMS with 10 items. Construct validity and reliability analyses confirmed that the CN-MMS was reliable and valid. Therefore, it can be used to investigate individual medical maximising and minimising tendencies among the general Chinese population. Further research is needed to replicate this study using a larger sample.

Acknowledgements The authors would like to thank Laura Scherer for granting permission to translate the original English version of the MMS into Chinese and further examine its psychometric properties among a Chinese population. She also generously offered advice. They would also like to thank all participants for their contributions to this study.

Contributors $\mathrm{JL}$ had the idea and designed the study. HX, XC and YL supervised the study. FL, LP and SY carried out the data collection and participated in data analysis. FL and $\mathrm{JL}$ drafted and revised the manuscript. All of the authors read and approved the final manuscript.

Funding The authors have not declared a specific grant for this research from any funding agency in the public, commercial or not-for-profit sectors.

Competing interests None declared.

Patient consent for publication Not required.

Ethics approval This study was approved by the Human Research Ethics Committee of The First Affiliated Hospital, Sun Yat-sen University (reference number: [2019]389). The information (main contents, purpose, and benefits) about this study was explained on the first page of the online questionnaire. The participants clicked the 'Yes' button on the first page of the online questionnaire to confirm their consents for this study.

Provenance and peer review Not commissioned; externally peer reviewed.

Data availability statement Data are available upon reasonable request. The data used to support the findings of this study are available from the corresponding author upon reasonable request.

Supplemental material This content has been supplied by the author(s). It has not been vetted by BMJ Publishing Group Limited (BMJ) and may not have been peer-reviewed. Any opinions or recommendations discussed are solely those of the author(s) and are not endorsed by BMJ. BMJ disclaims all liability and responsibility arising from any reliance placed on the content. Where the content includes any translated material, BMJ does not warrant the accuracy and reliability of the translations (including but not limited to local regulations, clinical guidelines, terminology, drug names and drug dosages), and is not responsible for any error and/or omissions arising from translation and adaptation or otherwise.

Open access This is an open access article distributed in accordance with the Creative Commons Attribution Non Commercial (CC BY-NC 4.0) license, which permits others to distribute, remix, adapt, build upon this work non-commercially, and license their derivative works on different terms, provided the original work is properly cited, appropriate credit is given, any changes made indicated, and the use is non-commercial. See: http://creativecommons.org/licenses/by-nc/4.0/.

ORCID iD

Fenghua Lai http://orcid.org/0000-0002-3562-7132

\section{REFERENCES}

1 Meng Q, Xu L, Zhang Y, et al. Trends in access to health services and financial protection in China between 2003 and 2011: a crosssectional study. Lancet 2012;379:805-14. 
2 Gu D, Zhang Z, Zeng Y. Access to healthcare services makes a difference in healthy longevity among older Chinese adults. Soc Sci Med 2009;68:210-9.

3 Guo B, Xie X, Wu Q, et al. Inequality in the health services utilization in rural and urban China: a horizontal inequality analysis. Medicine 2020;99:e18625.

4 Grossman DC, Curry SJ, et al, US Preventive Services Task Force. Screening for prostate cancer: US preventive services Task force recommendation statement. JAMA 2018;319:120-34

5 Prasad V, Cifu A, loannidis JPA. Reversals of established medical practices: evidence to abandon SHIP. JAMA 2012;307:37-8.

6 Prasad V, Cifu A. Ending medical reversal: improving outcomes, saving lives. Baltimore, MD: Johns Hopkins University Press, 2015.

7 Groopman JE, Hartzband P. Your medical mind: how to decide what is right for you. New York: Penguin Press, 2011.

8 Scherer LD, Caverly TJ, Burke J, et al. Development of the medical maximizer-minimizer scale. Health Psychol 2016;35:1276-87.

9 Evron JM, Reyes-Gastelum D, Banerjee M, et al. Role of patient maximizing-minimizing preferences in thyroid cancer surveillance. $J$ Clin Oncol 2019;37:3042-9.

10 Scherer LD, Kullgren JT, Caverly T, et al. Medical maximizing-minimizing preferences predict responses to information about prostate-specific antigen screening. Med Decis Making 2018;38:708-18.

11 Kang SK, Scherer LD, Megibow AJ, et al. A randomized study of patient risk perception for incidental renal findings on diagnostic imaging tests. AJR Am J Roentgenol 2018;210:369-75.

12 Eremenco SL, Cella D, Arnold BJ. A comprehensive method for the translation and cross-cultural validation of health status questionnaires. Eval Health Prof 2005;28:212-32.

13 Gao Y, Dai H, Jia G, et al. Translation of the Chinese version of the Nomophobia questionnaire and its validation among college students: factor analysis. JMIR Mhealth Uhealth 2020;8:e13561.

14 Graham JL, Lam NM. The Chinese negotiation. Harv Bus Rev 2003;81:82-91.

15 Lee $\mathrm{M}-\mathrm{H}$. [Applying confucian principles to the resolution of clinical ethical dilemmas in Taiwan]. Hu Li Za Zhi 2018;65:95-103.

16 Han Y, Zhou Y, Wang J, et al. Psychometric testing of the mandarin version of the 34-item short-form supportive care needs survey in patients with cancer in mainland China. Support Care Cancer 2017;25:3329-38.

17 Rong $\mathrm{X}$, Peng $\mathrm{Y}, \mathrm{Yu} \mathrm{H}$, et al. Factors associated with adoption of coping strategies among Chinese patients with heart failure in ethnic minority regions. J Clin Nurs 2018;27:3324-34.

18 Lu J, Zeng X, Liao J, et al. Effectiveness of an intervention to promote self-efficacy on quality of life of patients with nasopharyngeal carcinoma of the Zhuang tribe minority in Guangxi, China: a prospective study. Med Sci Monit 2017;23:4077-86.

$19 \mathrm{Qu} \mathrm{H}$, Lu Y, Gudbranson E, et al. Large-scale epidemiologic studies of cardiovascular diseases in China: need for improved data collection, methods, transparency, and documentation. Glob Heart 2018;13:3-12.

20 Huang Y, Shallcross D, Pi L, et al. Ethnicity and maternal and child health outcomes and service coverage in Western China: a systematic review and meta-analysis. Lancet Glob Health 2018;6:e39-56.

21 Stephens C, Nettleton C, Porter J, et al. Indigenous peoples' health--why are they behind everyone, everywhere? Lancet 2005;366:10-13.

22 Bor J, Cohen GH, Galea S. Population health in an era of rising income inequality: USA, 1980-2015. Lancet 2017;389:1475-90.

23 Kinge JM, Modalsli JH, Øverland S, et al. Association of household income with life expectancy and cause-specific mortality in Norway, 2005-2015. JAMA 2019;321:1916-25.

24 Welch HG, Fisher ES. Income and cancer overdiagnosis - when too much care is harmful. N Engl $J$ Med 2017;376:2208-9.

25 Yip WC-M, Hsiao WC, Chen W, et al. Early appraisal of China's huge and complex health-care reforms. Lancet 2012;379:833-42.

26 National Bureau of Statistics, 2010. Available: http://www.stats.gov. cn/tjsj/pcsj/rkpc/6rp/indexch.htm [Accessed 12 Dec 2020].

27 Basch E, Artz D, Dulko D, et al. Patient online self-reporting of toxicity symptoms during chemotherapy. J Clin Oncol 2005;23:3552-61.

28 van Gelder MMHJ, Bretveld RW, Roeleveld N. Web-based questionnaires: the future in epidemiology? Am J Epidemio 2010;172:1292-8. 